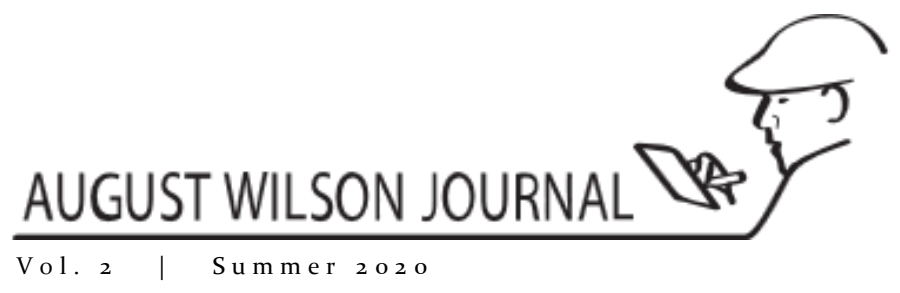

\title{
Erratum to Saunders, Skyler. "Unlocked Minds: August Wilson's Suspects, Ex-Cons, or Soon-to-Be Convicted Characters in his American Century Cycle." August Wilson Journal [Online], 2(2020): doi https://doi.org/10.5195/awj.2020.55
}

\author{
August Wilson Journal Editors
}

The article Saunders, Skyler. "Unlocked Minds: August Wilson's Suspects, Ex-Cons, or Soon-to-Be Convicted Characters in his American Century Cycle." August Wilson Journal [Online], 2 (2020): https://doi.org.10.5195/awj.2020.55 contained several errors in the original publication. The original version has been updated to reflect the following changes:

On page 1, the following sentence has been removed: "Black Lives Matter Foundation, Inc is a global organization in the US, UK, and Canada, whose mission is to eradicate white supremacy and build local power to intervene in violence inflicted on Black communities by the state and vigilantes." The Black Lives Matter group is not about individual rights but is run by Marxists. The error was introduced by the editors.

On page 3, the following section has been removed: "As of this writing, Blacks make up about 2.3 million of the 6.8 million or about $34 \%$ of incarcerated individuals, according to the NAACP. Former president of this organization Benjamin Jealous said, "Our country has five percent of the world's people and 25 percent of the world's prisoners. Now, you can flip that a different way, a Black person today in this country is more likely to be incarcerated than a Black person in South Africa at the height of apartheid" (NAACP)". There are in fact not 6.8 million incarcerated people in the US. There are actually 2.3 million people behind bars. The error was introduced by the author.



